\title{
Study on Fresh And Hardened Properties of High Strength Self Compacting Concrete With Metakaolin And Microsilica As Mineral Admixture (M70 Grade)
}

\author{
Shashikanth ${ }^{1,}$ Dr.V.Mallikarjuna Reddy ${ }^{2}$ \\ ${ }^{I}$ Student of M.Tech (Structural Engg.)Department of Civil Engineering GRIET Hyderabad, India \\ ${ }^{2}$ ProfessorDepartment of Civil Engineering GRIET Hyderabad, India
}

\begin{abstract}
This experimental study demonstrates that metakaolin (MK) \& Micro Silica(MS) can be successfully used as an admixture in the preparation of self-compacting concrete (HSSCC). In order to prepare suitable mix proportions for different grades of MK based HSSCC, investigations were undertaken replacing cement with 0\%, 10\%, 20\%, 30\%, 40\% of MK As per the European guidelines for Self-compacting concrete, slump flow test, $V$-funnel test and L-box test have been carried out on fresh properties of MK based HSSCC. The compressive strength, split tensile strength and flexural strength of the specimens have been analyzed for 7-days and 28 days curing. From the study it is observed that workability decreases with increase in Metakaolin. Whereas mechanical properties such as Compressive strength, Split tensile strength and Flexural strength test increase with increase in metakaolin up to $20 \%$ and decreases from $30 \%$ to $40 \%$. As metakaolin increases from $0 \%$ to $40 \%$, slump value decreases by $6.42 \% \%$, V funnel at T5 minutes value increases by $23.04 \%$ and L Box value decreases by $16.32 \%$ and U Box value increases by 33\%. The fresh concrete test results revealed that by substituting different percentages of MK in SCC, satisfactory workability and rheological properties can be achieved, by using viscosity modifying agent. In general, it seems that MK can be considered as suitable replacement regarding to the economic efficiency, fresh and hardened properties of MK based HSSCC. Non Destructive Test is also conducted to assess the quality of concrete in the hardened state. It was observed that quality of concrete is excellent for metakaolin replacement of 10\%\&20\% and good for $30 \%$ replacement. Whereas quality of concrete is satisfactory for a $40 \%$ replacement.
\end{abstract}

Keywords: Self Compacting concrete, Metakaolin, Micro silica NDT, Fresh and Hardened properties.

\section{Introduction}

The use of sustainable technologies such as supplementary cementitious materials (SCMs) is expected to positively affect the performance of concrete mixtures. Self Compacting Concrete (SCC) is an innovative development of conventional concrete, which requires high binder content to increase segregation resistance. SCC is a high flowable concrete, which can be placed and compacted without any vibration in complex or dense reinforced formworks. In order to achieve such behavior, the main requirements of fresh SCC are filling ability, passing ability and very high segregation resistance. The first two properties can be achieved by using a super plasticizer admixture. To secure stability/cohesion of the mix, a large quantity of powder materials and/or viscosity-modifying admixture (VMA) is required. The hardened SCC is dense, homogeneous and has the same engineering properties and durability as that of traditional vibrated concrete. The use of SCC eliminates the need for compaction thereby saves time, reduces labour costs and conserves energy. Furthermore use of SCC enhances surface finish characteristics. According to EFNARC, the term powder is defined for materials of particle size smaller than $0.125 \mathrm{~mm}$ which includes fraction of aggregate, additions and cement. Portland cement is a highly energy-intensive product. On the other hand, $\mathrm{CO} 2$ emmission are produced by the cement industry. In addition, some disadvantages in the properties of concrete have been reported as the cement content exceeded a specified value. To minimize these negative effects, the requirement to increase powder content in SCC is usually met by the use of additions. For this purpose, substantial studies have been performed on the usage of different additions for partially replacement of cement in SCC or self-compacted mortar such as marble powder, limestone powder, basalt powder, fly ash and slag. For instance, for fast track construction, early age compressive strength reduction may be unacceptable. The utilization of high pozzolanic activity materials seems to be an efficient choice to overcome this difficulty.

Metakaolin (MK) can also be considered as mineral admixture in the production of SCC. MK (commercially available since the mid-1990s) is a thermally activated alumino-silicate material mostly produced by calcination of kaolin clay at temperature ranging from $700^{\circ} \mathrm{C}$ to $850{ }^{\circ} \mathrm{C}$ without production of $\mathrm{CO} 2$. MK processing involves lower temperatures than Portland cement which may yield a lower cost on MK production. But, due to the low production of MK, the price will be raised up. Nonetheless, the usage of MK in concrete can be reasonable due to its environmental benefits and positive effect on the both short and long terms 
strength of concrete.In this respect, it has been reported that the use of MK in concrete can increase the compressive strength of mixtures especially during early ages of hydration. Poon et al. showed that at early ages, the higher pozzolanic activity of MK results in a higher rate of strength development and pore structure refinement when compared to silica fume -or fly ash- blended cement pastes. However, at the same level of replacement, MK concrete had similar strength after 28 days with respect to silica fume concrete. Kim et al. measured the concrete strength with Korean MK and suggested that $10 \%$ replacement of MK is an appropriate replacement. However, different aspects of normal concrete containing

MK have been reported in literature but to the authors' knowledge, the performance of MK in SCC is not well documented, particularly over a wide range of grades.In particular, the effects of MK as a high surface area mineral addition on the workability as well as mechanical properties of SCC need to be fully recognized. So, the present study is an effort to characterize the fresh and hardened properties of SCC containing MK.

For this purpose, several tests concerning slump flow, V-funnel and L-box were conducted to assess the workability of the matrix. Furthermore, hardened properties were evaluated by compressive strength, splitting tensile strength and flexural strength.

\subsection{General}

\section{Experimental Plan}

The scope of present work is to study on fresh and hardened properties of Self Compacting Concrete with metakaolin \& microsilica as mineral admixture (M70 Grade). The work focused on replacement of metakaolin $10 \%, 20 \%, 30 \%, 40 \%$ \&micro silica $8 \%$, with a Packing factor of 1.10 . The Concrete mixes contains different proportions of Metakaolin \& cement and constant proportions of waterbinder,microsilica, Coarse aggregate and Fine aggregate for constant water-cement ratios. The mix proportions are obtained on the basis of NAN-SU mix design. Non Destructive Test is also conducted to assess the quality of concrete in the hardened state.

\subsection{Materials}

The 53 grade ordinary Portland cement and MK (brought from 20 microns Ltd, Mumbai) were used as binder materials in the production of concrete mixes. The fine aggregate was natural river sand. Limestone gravel a nominal maximum size of $10 \mathrm{~mm}$ was used as coarse aggregate. Poly carboxylic ether based admixture namely Glenium B233 (brought from BASF) was used to enhance the flow ability of the mixtures. The physical properties of all the materials are shown in following tables.

Table: 1 Physical properties of Ordinary Portland cement

\begin{tabular}{|l|l|l|}
\hline S. No & Property & Test Results \\
\hline 1. & Normal Consistency & $30 \%$ \\
\hline 2. & Specific gravity & 2.9 \\
\hline 3. & $\begin{array}{l}\text { Initial setting time } \\
\text { Final setting time }\end{array}$ & $\begin{array}{l}99 \text { minutes } \\
207 \text { minutes } \\
\end{array}$ \\
& & $1.3 \%$ \\
\hline 4. & Fineness & $2 \mathrm{~mm}$ \\
\hline 5. & Soundness & \\
\hline
\end{tabular}

Table: 2 Physical properties of Fine aggregate and Coarse aggregate

\begin{tabular}{|l|l|l|l|}
\hline $\begin{array}{l}\text { S. } \\
\text { No }\end{array}$ & Property & $\begin{array}{l}\text { Fine } \\
\text { Aggregate }\end{array}$ & $\begin{array}{l}\text { Coarse } \\
\text { Aggregate }\end{array}$ \\
\hline 1. & Specific gravity & 2.42 & 2.6 \\
\hline 2. & $\begin{array}{l}\text { Bulk Density } \\
\text { Loose }\end{array}$ & $\begin{array}{l}1545.69 \\
\mathrm{~kg} / \mathrm{m}^{3}\end{array}$ & $1400 \mathrm{~kg} / \mathrm{m}^{3}$ \\
\hline 3. & Bulking & $4 \% \mathrm{w} \mathrm{c}$ & -- \\
\hline 4. & Flakiness Index & -- & $8 \%$ \\
\hline 5. & Elongation Index & -- & $0 \%$ \\
\hline 6. & Fineness Modulus & 2.64 & -- \\
\hline
\end{tabular}

Table: 3 Physical properties of Metakaolin

\begin{tabular}{|l|l|l|l|}
\hline S.No & Description of physical properties & Units & Results \\
\hline 1 & Color & & 1Close To Std \\
\hline 2 & Appearance & & OFF white Powder \\
\hline 3 & Bulk Density & Gm/liter & 356 \\
\hline 4 & Oil Absorption & Gm/100gm & \\
\hline 5 & Moisture (EX-Work) & $\%$ & 0.22 \\
\hline 6 & PH (10\% A2 Slurry) & & 6.22 \\
\hline 7 & RESIDUE on 325 Mesh & $\%$ & 0.13 \\
\hline 8 & PSD -D(50)- 50\% particles & $\mu$ & 1.68 \\
\hline 9 & Specific gravity & & 2.63 \\
\hline
\end{tabular}


Table: 4 Properties of Super plasticizer

\begin{tabular}{|l|l|l|}
\hline S. No & Property & Results \\
\hline 1. & Form or state & Liquid \\
\hline 2. & Color & Brown \\
\hline 3. & $\begin{array}{l}\text { Specific Gravity } \\
\text { Final setting time }\end{array}$ & 1.09 at $30^{\circ} \mathrm{C}$ \\
\hline
\end{tabular}

\subsection{Mix Proportions for M70 SCC (metakaolin variable)}

Table: 5 Mix Proportions for M70 SCC

\begin{tabular}{|l|l|l|l|l|l|}
\hline \multirow{3}{*}{ Mix Components } & \multicolumn{4}{|l|}{ Concrete Mixes } \\
\cline { 2 - 6 } & MIX 1 & MIX 2 & MIX 3 & MIX 4 & MIX 5 \\
& $0 \%$ & $10 \%$ & $20 \%$ & $30 \%$ & $40 \%$ \\
\cline { 2 - 6 } & Qty. & Qty. & Qty. & Qty. & Qty. \\
\hline CEMENT & 574.02 & 517.00 & 459.216 & 401.81 & 344.41 \\
\hline C.A & 790.94 & 790.94 & 790.94 & 790.94 & 790.94 \\
\hline F.A & 829.4 & 829.4 & 829.4 & 829.4 & 829.4 \\
\hline WATER & 173.26 & 173.26 & 173.26 & 173.26 & 173.26 \\
\hline METAKAOIN & 52.400 & 109.802 & 167.2 & 224.608 & 282.08 \\
\hline S.P & 11.28 & 11.28 & 11.28 & 11.28 & 11.28 \\
\hline MICRO SILICA & 40.18 & 40.18 & 40.18 & 40.18 & 40.18 \\
\hline V.M.A & 1.722 & 1.722 & 1.722 & 1.722 & 1.722 \\
\hline
\end{tabular}

\subsection{Tests on Fresh Concrete}

The test mentioned in Table 6 was conducted to assess whether the mixes meet the workability requirements of SCC.The results of tests conducted on fresh concrete are given in Table 7.

Table: 6 Methods for testing workable properties of SCC

\begin{tabular}{|l|l|l|}
\hline S.No & METHOD & PROPERTY \\
\hline 1 & Slump flow by Abrams cone & Filling ability \\
\hline 2 & T $_{50}$ Slump flow & Filling ability \\
\hline 3 & V-Funnel & Filling ability \\
\hline 4 & V-Funnel at T5 minutes & Segregation resistance \\
\hline 5 & L-Box test & Passing ability \\
\hline 6 & U-Box test & Passing ability \\
\hline
\end{tabular}

Table: 7 Fresh properties of M70 SCC

\begin{tabular}{|l|l|l|l|l|l|}
\hline \multirow{2}{*}{ Workability Tests } & \multicolumn{4}{l}{ Concrete Mixes } \\
\cline { 2 - 6 } & MIX 1 & MIX 2 & MIX 3 & MIX 4 & MIX 5 \\
& $0 \%$ & $10 \%$ & $20 \%$ & $30 \%$ & $40 \%$ \\
\hline Slump flow (mm) & $700 X 7$ & $695 X 69$ & $685 X 68$ & $670 X 670$ & $655 X 655$ \\
& 00 & 5 & 5 & & \\
\hline T 500(sec) & 4.12 & 4.2 & 4.45 & 4.75 & 4.98 \\
\hline V-funnel(sec) & 9.12 & 10.65 & 11.35 & 11.5 & 11.8 \\
\hline V-funnel T5min(sec) & 12.15 & 13.20 & 14.35 & 14.65 & 14.95 \\
\hline L-box(h2/h1) & 0.98 & 0.95 & 0.92 & 0.85 & 0.82 \\
\hline U-box (mm) & 3 & 4 & 5 & 6 & 7 \\
\hline
\end{tabular}

Table: 8 Acceptance criteria for SCC (as per EFNARC)

\begin{tabular}{|l|l|l|l|}
\hline \multirow{2}{*}{ Method } & \multirow{2}{*}{ Unit } & \multicolumn{2}{|l|}{ Typical range of values } \\
\cline { 3 - 4 } & & Min & Max \\
\hline Slump flow by Abrams cone & $\mathrm{mm}$ & 650 & 800 \\
\hline $\mathrm{T}_{50}$ slump-flow & $\mathrm{Sec}$ & 2 & 5 \\
\hline V-funnel & $\mathrm{Sec}$ & 6 & 12 \\
\hline V-funnel at T5 minutes & $\mathrm{Sec}$ & 6 & 15 \\
\hline L-Box & $\mathrm{H}_{2} / \mathrm{H}_{1}$ & 0.8 & 1.0 \\
\hline U-Box & $\left(\mathrm{h}_{2}-\mathrm{h}_{1}\right) \mathrm{mm}$ & 0 & 30 \\
\hline
\end{tabular}

From Table 7 and 8 , it is observed that all mix proportions satisfy the workability requirements of Self Compacting Concrete.

\subsection{Compressive Strength Tests}

Compressive strength tests were conducted on $100 \mathrm{~mm}$ size cubes of SCC in a compression testing machine at 7 and 28 days. The results are given in Table 9 and plotted in Fig.1. 
Table: 9 Compressive Strength Results

\begin{tabular}{|l|l|l|}
\hline \multirow{2}{*}{ Type of mix } & \multicolumn{2}{l|}{$\begin{array}{l}\text { Compressive Strength } \\
(\mathrm{N} / \mathrm{mm} 2)\end{array}$} \\
\cline { 2 - 3 } & 7 days & 28days \\
\hline MIX 1 (0\%) & 54.95 & 78.5 \\
\hline MIX 2 (10\%) & 57.715 & 82.45 \\
\hline MIX 3 (20\%) & 58.177 & 83.11 \\
\hline MIX 4 (30\%) & 54.93 & 78.48 \\
\hline MIX 5 (40\%) & 54.544 & 77.92 \\
\hline
\end{tabular}

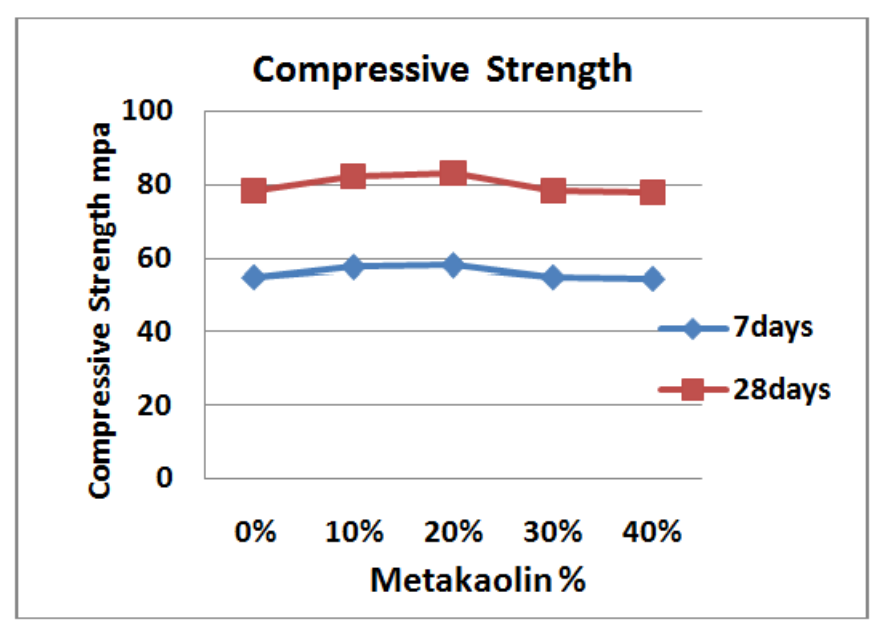

Figure 1: Metakaolin Vs Compressive strength

From Table 9 and Fig.1, it is observed that as the Metakaolin increases compressive strength decreases this is due to increase in powder content.

\subsection{Split Tensile Strength Tests}

Splitting tensile strength tests were conducted on cylindrical specimens of $150 \mathrm{~mm}$ diameter and 300 $\mathrm{mm}$ height at 7 and 28 days in accordance with BIS specifications and procedures. The results are given in Table 10 .

Table: 10 Split Tensile Strength Results

\begin{tabular}{|l|l|l|}
\hline \multirow{2}{*}{ Type of mix } & \multicolumn{2}{|l|}{ Split Tensile Strength (N/mm2 ) } \\
\cline { 2 - 3 } & 7 days & 28days \\
\hline MIX 1 (0\%) & 3.65 & 4.04 \\
\hline MIX 2 (10\%) & 3.85 & 4.242 \\
\hline MIX 3 (20\%) & 3.965 & 4.284 \\
\hline MIX 4 (30\%) & 3.765 & 4.069 \\
\hline MIX 5 (40\%) & 3.38 & 3.743 \\
\hline
\end{tabular}

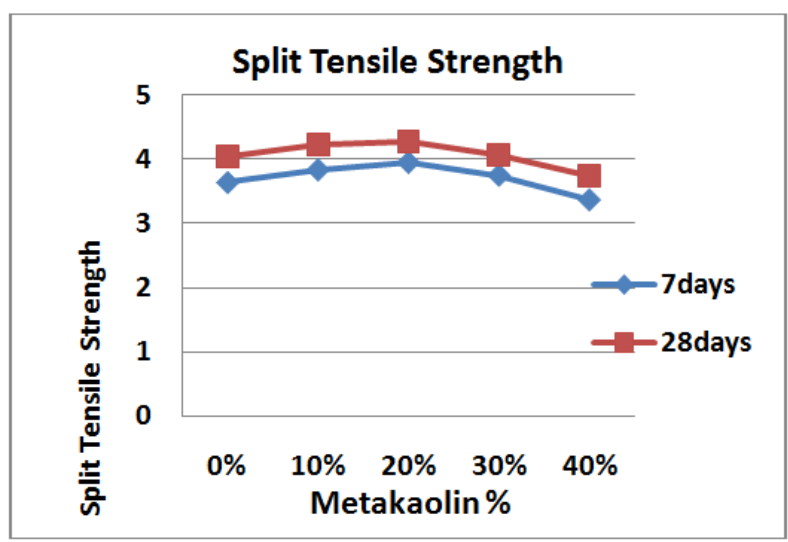

Figure 2: Metakaolin Vs Split Tensile strength

From Table 10 and Fig.2, it is observed that as the water cement ratio increases split tensile strength decreases this is due to increase in powder content. 


\subsection{Flexural Strength Tests}

Flexural tests were conducted on beams of size of $100 \mathrm{~mm}$ x 100mm X $500 \mathrm{~mm}$ subjected to two point loading at 28 days in UTM and the results were given in Table 11. These results are plotted in Fig.3.

Table: 11 Flexural Strength Results

\begin{tabular}{|l|l|l|}
\hline \multirow{2}{*}{ Type of mix } & \multicolumn{2}{|l|}{ Flexural Strength (N/mm2 ) } \\
\cline { 2 - 3 } & 7 days & 28 days \\
\hline MIX 1 (0\%) & 5.18 & 6.201 \\
\hline MIX 2 (10\%) & 5.32 & 6.352 \\
\hline MIX 3 (20\%) & 5.33 & 6.381 \\
\hline MIX 4 (30\%) & 5.19 & 6.2 \\
\hline MIX 5 (40\%) & 5.16 & 6.179 \\
\hline
\end{tabular}

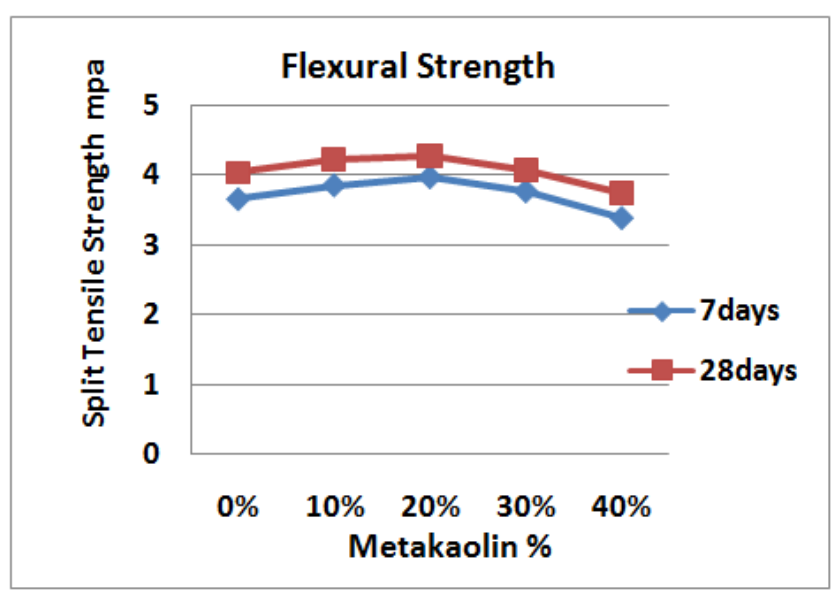

Figure 3: Water cement Ratio Vs Flexural strength

\subsection{Non Destructive Tests}

The main objective of the present experimental investigations is to assess the quality, structural integrity and estimated compressive strength of metakaolin incorporated self compacting concrete of grade M70 using Rebound hammer and Ultrasonic pulse velocity measurements.

\subsection{Rebound Hammer Test}

Rebound hammer is the oldest technique used to assess the compressive strength of concrete indirectly and also to compare the various parts of structure. Schmidt rebound hammer is the instrument for this test Schmidt rebound hammer shown in Fig1 is a simple, handy tool, which can be used to provide a convenient and rapid indication of the compressive strength of concrete. It consists of a spring controlled mass that slides on a plunger within a tubular housing.It works on the principle that the rebound of an elastic mass depends on the hardness of the surface against which the mass impinges.

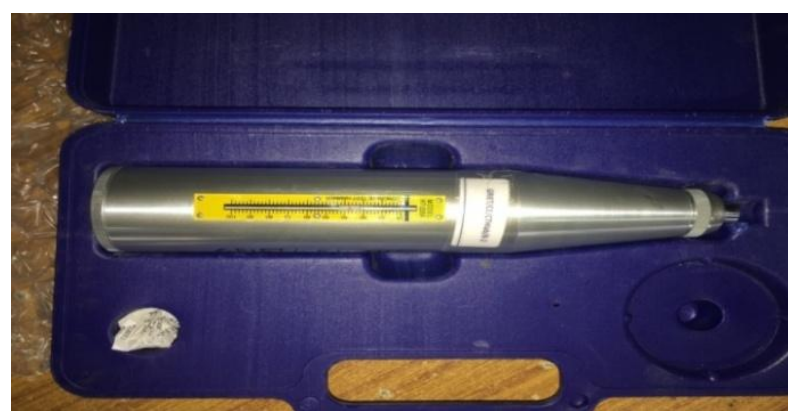

Figure 3 : Rebound hammer used

Table: 12 Quality of concrete based on Average Rebound Hammer

\begin{tabular}{|l|l|}
\hline Average rebound number & Quality of concrete \\
\hline \multicolumn{1}{|c|}{$>40$} & Very good hard layer \\
\hline 30 to 40 & Good layer \\
\hline 20 to 30 & Fair \\
\hline$<20$ & Poor \\
\hline
\end{tabular}




\subsection{Ultrasonic Pulse Velocity Test}

Three reading of ultrasonic pulse velocity (USPV) were obtained for each cube. The cubes were then give a load of $7 \mathrm{~N} / \mathrm{mm} 2$ (as specified by the IS code 13311) in the compression testing machine and the USPV were obtained. The cubes were then loaded upto their ultimate stress and the breaking load was obtained. The method starts with the determination of the time required for a pulse vibrations at an ultrasonic frequency to travel through a concrete. Once the velocity is determined, an idea about quality, uniformity, condition and strength of the concrete tested can be attained. In the test, the time the pulses take to travel through concrete is recorded. Then the velocity is calculated as:

$\mathbf{V}=\mathbf{L} / \mathbf{T}$

Where

$\mathrm{V}=$ Pulse Velocity, $\mathrm{L}=$ travel time in meters and

$\mathrm{T}=$ effective time in seconds

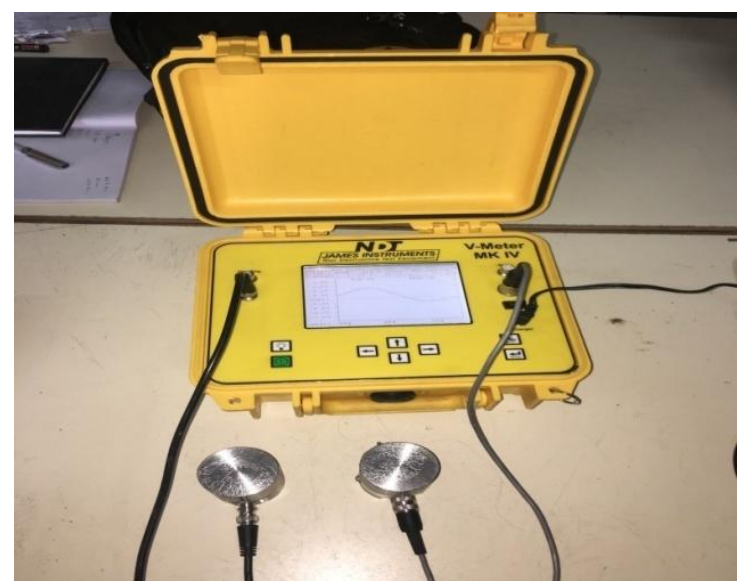

Figure 10: Ultrasonic Pulse Velocity used

Table: 13 General Guidelines for Concrete Quality based on USPV

\begin{tabular}{|l|l|}
\hline Pulse Velocity & Quality of concrete \\
\hline \multicolumn{1}{|c|}{$4.0 \mathrm{~km} / \mathrm{s}$} & Very good to excellent \\
\hline 3.5 to $4.0 \mathrm{~km} / \mathrm{s}$ & Good to very good, slightly porosity may exist \\
\hline 3.0 to $3.5 \mathrm{~km} / \mathrm{s}$ & Satisfactory but loss of integrity may exist \\
\hline$<3.0 \mathrm{~km} / \mathrm{s}$ & Poor and loss of integrity exist \\
\hline
\end{tabular}

Table: 14 Non-destructive test results of M70 grade SCC

\begin{tabular}{|l|l|l|l|l|}
\hline \multirow{5}{*}{$\%(M K)$} & \multicolumn{4}{l|}{$\begin{array}{l}\text { Combined Rebound hammer and Ultrasonic Pulse Velocity } \\
\text { Methods Results }\end{array}$} \\
\cline { 2 - 5 } & M70 Concrete, Mpa \\
\cline { 2 - 5 } & $\begin{array}{l}\text { Mean } \\
\text { Rebound } \\
\text { Value }\end{array}$ & $\begin{array}{l}\text { Mean Pulse } \\
\text { Velocity } \\
\mathbf{k m} / \mathbf{s e c}\end{array}$ & $\begin{array}{l}\text { Compressive } \\
\text { Strength } \\
\text { N/mm2 }\end{array}$ & $\begin{array}{l}\text { Quality of } \\
\text { Concrete }\end{array}$ \\
\hline $0 \%$ & 31.5 & 3.6 & 79.8 & Good \\
\hline $10 \%$ & 42.4 & 4.03 & 83.25 & Excellent \\
\hline $20 \%$ & 44.3 & 4.12 & 82.1 & Excellent \\
\hline $30 \%$ & 32.1 & 3.5 & 78.5 & Good \\
\hline $40 \%$ & 28.5 & 3.4 & 78 & satisfactory \\
\hline
\end{tabular}

From the above results it was observed that quality if concrete is excellent for replacement for $10 \% \& 20 \%$ and good for replacement for $30 \%$. whereas quality of concrete is satisfactory for $40 \% \mathrm{v}$ replacement.

\subsection{Discussion on proportions of mix}

\section{Discussion Of Test Results}

The mix proportions of SCC for M70 grade of concrete obtained "on the basis of Nan Su method" is shown in the Table 5 for different percentage of metakaolin Viz. 0\%,10\%,20\%,30\% and 40\% by keeping PF as 1.10. It was noted that, as the metakaolin $\%$ increases from $0 \%$ to $40 \%$, the powder content increases and the aggregate content remains the same. For the mix proportions obtained, Tables 7 and 9,10,11 shows the details of fresh properties and mechanical properties for various metakaolin percentages. 


\subsection{Effect of metakaolin on fresh properties}

The workability decreased with the increase in the metakaolin. This is because of increase in metakaolin .

As the metakaolin increases from $0 \%$ to $10 \%$ Slump value decreases by $0.714 \%$, T500 value increased by $1.94 \%, \mathrm{~V}$ funnel value incresed by $16.77 \%, \mathrm{~V}$ funnel at $\mathrm{T} 5$ minutes incresed by $5 \%, \mathrm{~L}$ box value decresed by $3.06 \%$, U box value increses by $33.33 \%$. As the metakaolin increases from $0 \%$ to $20 \%$ Slump value decreases by $2.142 \%$, T500 value increased by $8.09 \%$, V funnel value incresed by $24.45 \%$, V funnel at T5 minutes increase by $18.1 \%$, L box value decreased by $16.122 \%$, U box value increases by $66.67 \%$. As the metakaolin increases from $0 \%$ to $30 \%$ Slump value decreases by $4.285 \%$, T500 value increases by $15.29 \%$, V funnel value increases by $26.096 \%, \mathrm{~V}$ funnel at $\mathrm{T} 5$ minutes increases by $20.57 \%, \mathrm{~L}$ box value increases by $13.26 \%$, U box value increase by $100 \%$.

As the metakaolin increases from $10 \%$ to $40 \%$ Slump value decreases by $6.42 \%$, T500 value increases by $18.93 \%, \mathrm{~V}$ funnel value increases by $29.385 \%$, V funnel at $\mathrm{T} 5$ minutes increases by $23.04 \%, \mathrm{~L}$ box value increases by $16.32 \%$, U box value increases by $133 \%$. From the above results we observed that the workability decreases gradually as the percentage of metakaolin increases from $0 \%$ to $40 \%$. Further it is observed that the change in the percentage variation of flow values increases as the percentage of metakaolin increases from $10 \%$ to $20 \%, 20 \%$ to $30 \%$, and $30 \%$ t o $40 \%$ the reason for this is the powder content increases as the water cement ratio is constant.

\subsection{Effect of metakaolin on hardened properties}

The results of the mechanical properties such as compressive strength, split tensile strength and flexural strength are noted by testing the specimens "as per Indian standard test procedures (as per IS: 516)" are presented in Table 9,10,11. As the metakaolin increases from $0 \%$ to $10 \%$ Compressive Strength increases by $5.03 \%$, Split Tensile Strength increases by $5.47 \%$, Flexural Strength increases by $2.70 \%$.

As the metakaolin increases from $0 \%$ to $20 \%$ Compressive Strength increases by $5.87 \%$, Split Tensile Strength increases by $2.89 \%$, Flexural Strength increases by $8.63 \%$.As the metakaolin increases from $0 \%$ to $30 \%$ Compressive Strength decreases by $0.036 \%$, Split Tensile Strength decreases by $3.15 \%$, Flexural Strength decreases by $0.193 \%$ As the metakaolin increases from $0 \%$ to $40 \%$ Compressive Strength decreases by $0.73 \%$, Split Tensile Strength decreases by $7.39 \%$, Flexural Strength decreases by $0.386 \%$. From the above results it is observed that the strength increases gradually as percentage of metakaolin increases from $0 \%$ to $20 \%$.And strength decreases gradually as percentage of matakaolin increases from $30 \%$ to $40 \%$.Further it is observed that the change in the percentage variation of strength values increases as the percentage of metakaolin increases from $10 \%$ to $20 \%$ and decreases from $30 \%$ to $40 \%$, the reason for this is the powder content increases as the cement ratio is constant as per the Nan-Su mix design calculations.

\subsection{Non Destructive Evaluation}

Mean Rebound values and Mean Ultrasonic Pulse Velocities are measured to understand the quality, integrity and strength of Self Compacting Concrete. From the results it is observed that the surface hardness and quality of concrete are Excellent for percentage 10\% and 20\%. For replacement $30 \%$ the quality of concrete is good. For ratio $40 \%$ the quality of concrete is satisfactory.

As the replacement rises from $0 \%$ to $40 \%$,

\section{Conclusions}

- The powder content increases and the aggregate content remains the same.

- The workability decreases gradually as the percentage increases from $0 \%$ to $40 \%$.

- The change in the percentage variation of flow values decreses as the percentage of metakaolin increases from $10 \%$ to $20 \%$ and $30 \%$ to $40 \%$, the reason for this is the powder content increases as the water cement ratio is constant.

- The compressive strength, split tensile strength and flexural strength incresed with the increase in the percentage of metakaolin from $0 \%$ to $20 \%$ \& decreases from $30 \%$ to $40 \%$.

- The percentage variation of strength values increases as the percentage of metakaolin increases from $0 \%$ to $20 \%$ and decreases from $30 \%$ to $40 \%$ the reason for this is the powder content increases as the water cement ratio is constant .It leads to decrease the binding capacity of the concrete mix.

- The optimum percentage of metakaolin is taken as $20 \%$ for $\mathrm{w} / \mathrm{c}=0.27$.

- The presence of metakaolin improved both early ages and long term compressive strength of HSSCC. Based on the Non Destructive Tests it is concluded that quality of concrete,

- Is Excellent for metakaolin $10 \%$ and $20 \%$

- Is Good for metakaolin $30 \%$.

- Is Medium for metakaolin $40 \%$ 


\section{References}

[1]. Nan Su, Kung-Chung Hsu, His-WenChai “A Simple Mix Design Method for Self-Compacting Concrete” Cement and concrete Research 31 (2001) 1799-1807.

[2]. Okamura, H. and Ouchi, M., (2003). "Self-compacting concrete”, Journal of Advanced Concrete Technology, Vol. 1, No. 1, April, pp. 5-15.

[3]. Naveen Kumar C. Jagadish V and Ranganath R.V." Self-Compacting Concrete with Fly Ash and Metakaolin", The Indian Concrete Journal, April 2006, pp33-39.

[4]. The European Guidelines for Self Compact Concrete Specification, Productuion and Use Feb 2002 and May 2005

[5]. V.Mallikarjuna Reddy, M.V. Seshagiri Rao, P. Srilakshmi and K. Venkateswarlu "Effect of Packing Factor on workability and Mechanical Properties of Self-Compacting Concrete of M70 Grade with Fly Ash and Micro Silica as filler Material".

[6]. Subramanian .S and Chatopadyay.D“Experiments for mix proportions of Self Compacting Concrete", The Indian Concrete journal, Jan 2002, pp.13-20.

[7]. Okamura, H. and Ouchi, M., "Self-compacting concrete-development, present and future", Proceedings of the First International RILEM symposium on Self-Compacting Concrete, pp. 3-14.

[8]. SeshgiriRao. M.V., Janardhan.M. Ravindra Kumar. B. "High Fly Ash Concrete with RHA as an admixture".1999. Vol.80. Journal of Institution of Engineers, (India).pp.57-63.

[9]. P J Tikalsky, P M Carrasquillo and R L Carrasquillo. "Strength and Durability Considerations affecting Mix proportioning of Concrete Containing Fly Ash". ACi Materials journal, Vol 85,1998.

[10]. Www.efnarc.org:European Specifications and guidelines for Production \& Use of SCC, February and May 2005.

[11]. EFNARC guidelines for Specifications and guidelines for Self-compacting concrete, February 2002

[12]. EFNARC guidelines for Viscosity Modifying Agents.

[13]. www.basf-cc.co.in. (Gelenium).

[14]. Indian Code of Practice for Plain \& Reinforced Concrete IS 456.

[15]. IS 2386-1963, Method of Tests for Aggregates for cement. 